\title{
ATLAS Magnet System Nearing Completion
}

\author{
Herman H. J. ten Kate
}

\begin{abstract}
The ATLAS Detector at the Large Hadron Collider at CERN is equipped with a superconducting magnet system that consists of a Barrel Toroid, two End-Cap Toroids and a Central Solenoid. The four magnets generate the magnetic field for the muonand inner tracking detectors, respectively. After 10 years of construction in industry, integration and on-surface tests at CERN, the magnets are now in the underground cavern where they undergo the ultimate test before data taking in the detector can start during the course of next year. The system with outer dimensions of $25 \mathrm{~m}$ length and $22 \mathrm{~m}$ diameter is based on using conduction cooled aluminum stabilized NbTi conductors operating at $4.6 \mathrm{~K}$ and $20.5 \mathrm{kA}$ maximum coil current with peak magnetic fields in the windings of $4.1 \mathrm{~T}$ and a system stored magnetic energy of 1.6 GJ. The Barrel Toroid and Central Solenoid were already successfully charged after installation to full current in autumn 2006. This year the system is completed with two End Cap Toroids. The ultimate test of all toroids by which maximum mechanical and thermal loads are exerted is being prepared and will be performed late 2007 where after normal operation will commence. The status of the project in its nearly completed state as well as the first experience with testing and operation in the underground cavern are reported.
\end{abstract}

Index Terms-Particle detectors, solenoid, superconducting magnet, toroid.

\section{INTRODUCTION}

A TLAS, abbreviation for Apparatus Toroidal Large Aperture Spectrometer, is one of the two new general purpose particle detectors at the Large Hadron Collider presently being installed and commissioned at CERN. Proton-proton collision products will be analyzed in the ATLAS Experiment starting in 2008. To separate charged from non-charged particles and measure their momentum a bending magnetic field is required.

In ATLAS, see Fig. 1, the inner tracking detectors in the heart of the detector are served by the Central Solenoid while the outer shell with muon detectors are provided with magnetic field generated by three toroids, one large Barrel Toroid covering the radial direction and two End Cap Toroids covering the low-angle forward direction.

The four superconducting magnets in this hybrid system are based on the use of Al stabilized NbTi cables wound into fully potted windings, conduction cooled and operating at about $4.6 \mathrm{~K}$ by forced circulation of $1200 \mathrm{~g} / \mathrm{s}$ liquid Helium through cooling pipes attached to the cold masses. The main magnet system parameters are listed in Table I. Design and manufacturing features were reported during the past 10 years at several occasions [1], [2].

Manuscript received August 27, 2007. This work was funded by the ATLAS Collaboration, presently about 1900 scientific authors from 164 institutes in 35 countries worldwide, and is supported in part by CERN.

The author is with CERN, the European Organization for Nuclear Research, Geneva, Switzerland (e-mail: herman.tenkate@cern.ch).

Digital Object Identifier 10.1109/TASC.2008.921226
The installation of the entire magnet system in the ATLAS cavern $100 \mathrm{~m}$ underground at CERN is completed in 2007. Test and final commissioning are in progress and will be completed by early 2008 where after the system is available for the first physics experiments using the LHC.

\section{Central Solenoid}

The $2.5 \mathrm{~m}$ bore-sized and $5.3 \mathrm{~m}$ long Central Solenoid serving the inner detectors with $2 \mathrm{~T}$ bending field is produced and factory tested [3], shipped to CERN and re-tested on surface before installation underground. The $39 \mathrm{MJ}$ light-weight coil of 5.6 tonne and operating at $7.6 \mathrm{kA}$ passed successfully its commissioning test in the cavern in summer 2006. The coil survived all fault scenarios tested and in the case of a quench the maximum temperature remains below $120 \mathrm{~K}$ [4]. A full description of the coil design, coil production and various tests can be found elsewhere [5]. The coil is now in stand-by mode waiting for start of detector operation.

\section{BARREL TOROID}

The large Barrel Toroid, sized $22 \mathrm{~m}$ in diameter and $25 \mathrm{~m}$ in length, is built up from eight $25 \mathrm{~m} \times 5 \mathrm{~m}$ size racetrack coils equally spaced in a torus shape using interlinking warm structure beam elements.

The coil and structural components are built in industry but cold mass [6], cryostat integration [7] and single coil tests before installation [8] were performed at CERN. The various steps in production and testing were successful and the toroid installation in the cavern, see Fig. 2, was completed.

The eight coils are interconnected by eight cryoring segments that house the helium distribution lines and cold bus bars to the individual coils.

The magnets are connected to the proximity cryogenic system through transfer lines. This equipment is positioned on top of the detector and built against the cavern wall, see Fig. 3 .

Cool down and stand-alone test took place in 2006. The cool down of the 360 ton cold mass to $4.6 \mathrm{~K}$ takes 5 weeks. The magnet system cryogenics behaved very well.

The test program essentially covered normal ramps up to nominal current $(2 \mathrm{hr})$ followed by either a slow dump ( $2 \mathrm{hr})$ or a fast dump (2 min) in the case of a provoked quench. The ultimate test sequence that proved the system's health is shown in Fig. 4. In steps the magnet current is raised up to $20.5 \mathrm{kA}$ nominal value, a surplus of 500 A proven and a fast dump provoked. After re-cooling the cycle was repeated demonstrating that no degradation below nominal operation levels is occurred.

During a fast dump, triggered manually or by the quench detection system, the stored energy of $1.1 \mathrm{GJ}$ is absorbed by the enthalpy of the cold mass following the activation of four quench heaters per coil and in all 8 coils. A normal zone propagation of $10-15 \mathrm{~m} / \mathrm{s}$ then forces the entire magnet in the normal state in 


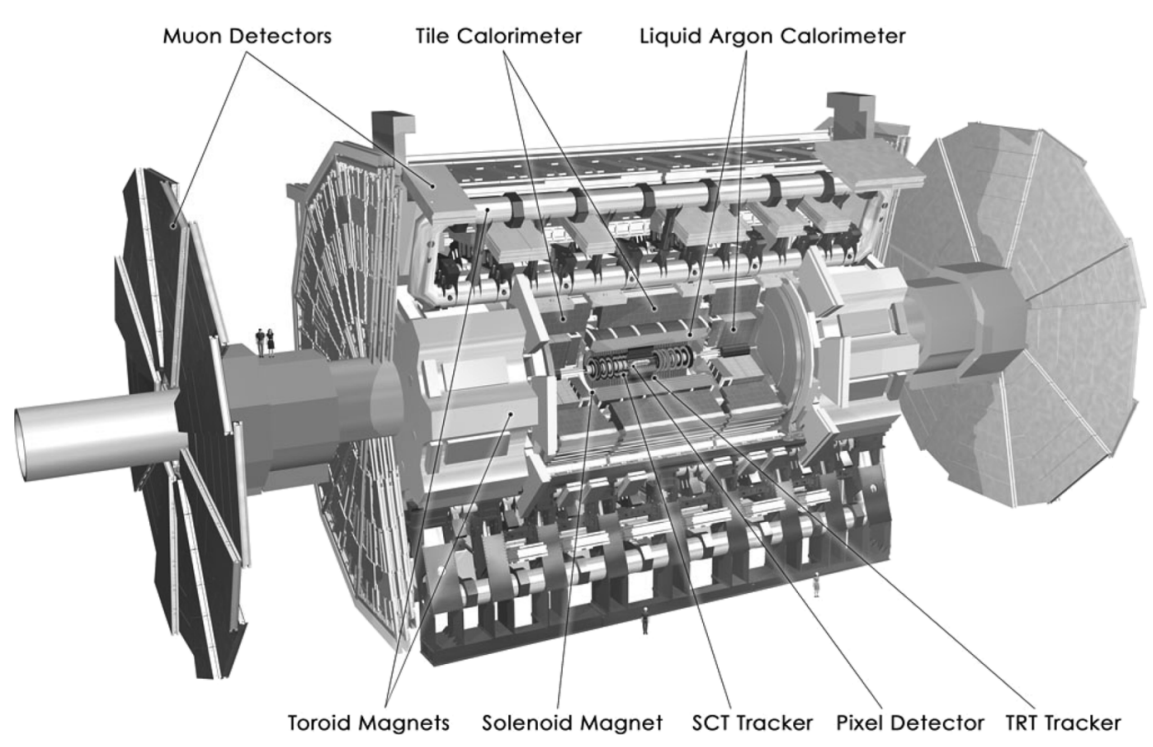

Fig. 1. Schematic layout of the ATLAS experiment. A barrel toroid and two end cap toroids provide magnetic field for the muon detectors in radial and forward directions, respectively. The central solenoid generates the magnetic field used by the tracker and pixel detectors positioned around the collision point in the center of the plot. The dimensions of the barrel toroid are $25 \mathrm{~m}$ in length and $22 \mathrm{~m}$ in diameter while the overall length of the experiment is $44 \mathrm{~m}$.

TABLE I

MAIN PARAMETERS OF THE MAGNETS

\begin{tabular}{|c|c|c|c|c|}
\hline Property & Unit & $\begin{array}{l}\text { Barrel } \\
\text { Toroid }\end{array}$ & $\begin{array}{l}\text { End Cap } \\
\text { Toroids }\end{array}$ & $\begin{array}{c}\text { Central } \\
\text { Solenoid }\end{array}$ \\
\hline Inner diameter & $\mathrm{m}$ & 9.4 & 1.65 & 2.46 \\
\hline Outer diameter & $\mathrm{m}$ & 20.1 & 10.7 & 2.63 \\
\hline Axial Length & $\mathrm{m}$ & 25.3 & 5 & 5.3 \\
\hline Number of Coils & -- & 8 & $2 \times 8$ & 1 \\
\hline Conductor & $\mathrm{t}$ & 118 & $2 \times 20.5$ & 3.8 \\
\hline Cold mass & $\mathrm{t}$ & 370 & $2 \times 160$ & $\overline{5.4}$ \\
\hline Total assembly & $\bar{t}$ & 830 & $2 \times 239$ & 5.7 \\
\hline Turns/coil & -- & 120 & 116 & 1173 \\
\hline Nominal current & $\mathrm{kA}$ & 20.5 & 20.5 & 7.6 \\
\hline Magnet stored energy & GJ & 1.08 & $2 \times 0.25$ & 0.04 \\
\hline Peak field in windings & $\mathrm{T}$ & 3.9 & 4.1 & 2.6 \\
\hline Conductor: overall size & $\mathrm{mm}^{2}$ & $57 \times 12$ & $41 \times 12$ & $30 \times 4.25$ \\
\hline Ratio Al:Cu:NbTi & -- & $28: 1.3: 1$ & $19: 1.3: 1$ & 15.6:0.9:1 \\
\hline No of strands & -- & $38-40$ & 40 & 12 \\
\hline Strand diameter & $\mathrm{mm}$ & 1.3 & 1.3 & 1.22 \\
\hline Critical current@,5T,4.2K & $\mathrm{kA}$ & 58 & 60 & 20.4 \\
\hline$\overline{\mathrm{RRR}}$ of $\mathrm{Al}$ & -- & $>800$ & $>800$ & $>400$ \\
\hline I/Ic margin @ $4.5 \mathrm{~K}$ & $\%$ & 30 & 30 & 20 \\
\hline Total length & $\mathrm{km}$ & 56 & $2 \times 13$ & 10 \\
\hline Heat Load: & $\overline{\mathrm{W}}$ & 900 & $2 \times 300$ & 130 \\
\hline at $\sim 70 \mathrm{~K}$ & $\mathrm{~kW}$ & 7.4 & $2 \times 1.7$ & 0.50 \\
\hline Liquid He mass flow & $\mathrm{g} / \mathrm{s}$ & 410 & $2 \times 280$ & 7 \\
\hline
\end{tabular}

less than $2 \mathrm{~s}$. This leads to a very safe global cold mass temperature of about $58 \mathrm{~K}$ and a hot-spot temperature in the windings of about $85 \mathrm{~K}$ maximum [9], [10]. By using the uniform quench heating system also the internal voltage in the toroid is kept at a low value of about $70-80 \mathrm{~V}$.

After a fast dump the magnet cooling system needs about 50 hours to re-cool the toroid to $4.6 \mathrm{~K}$. More information on

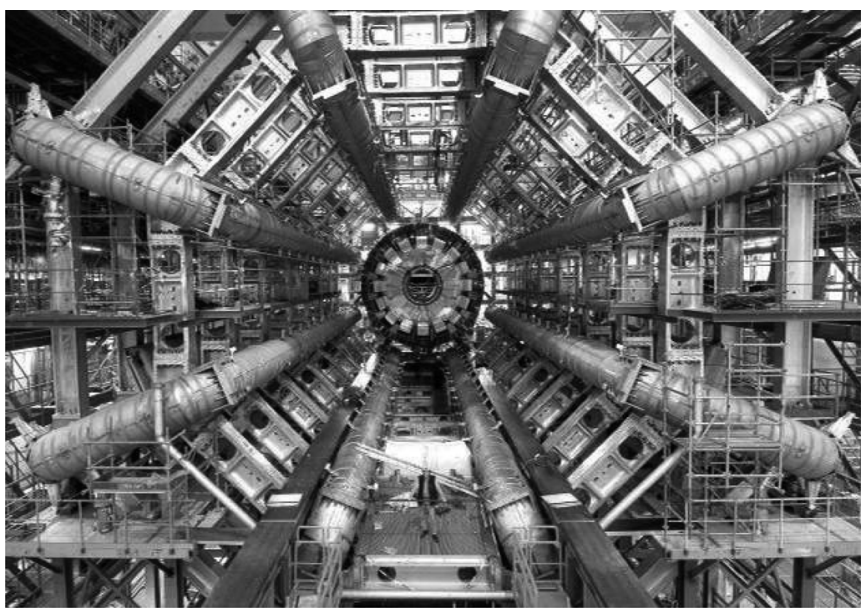

Fig. 2. Barrel toroid in bare state immediately after its installation. The 8 coils are interconnected by an inner and outer ring of struts to shape the torus.

the magnet system cooling plant and experience with the toroid cryogenics operation is published elsewhere [11]-[14].

The toroid external mechanical structure characterized by the maximum vertical deflection of $26-28 \mathrm{~mm}$ under self-and 400 tons extra weight of services other detector elements, is as calculated [15], [16]. The internal coil suspensions system comprising per coil eight Ti tie rods, 32 cold stops and a fixed point behaved reversibly and did not show any sign of degradation [17]-[19].

It is important to realize that neither training, nor any other spontaneous quench was observed in this new toroid of record size, which convincingly validates the mechanical and thermal design and production techniques of coils, bus interconnections and current lead cryostat. The system is safe to operate.

\section{END CAP TOROIDS}

Coil modules, thermal shield, MLI, coil suspension parts and vacuum vessel were produced in industry but the integrations of cold mass, cryostat and connections to services are performed on CERN site. The various stages of cold mass integration were 


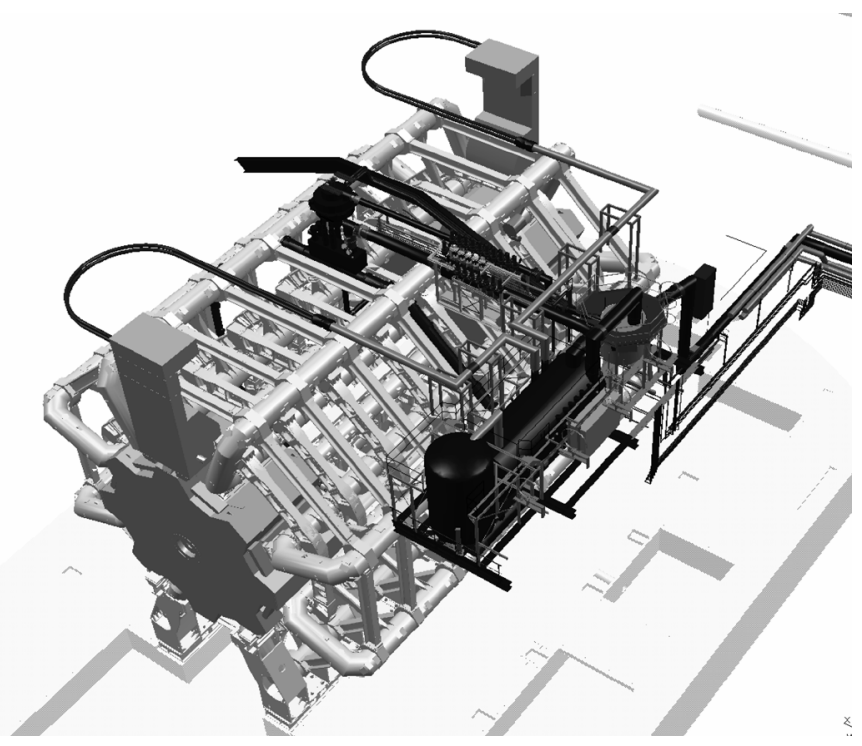

Fig. 3. Magnet cryogenics services arranged on top of the detector. Helium gas and liquid helium feed lines arrive from the shield and main refrigerator at the upper right corner in the cavern and run into distribution valves boxes, an $11 \mathrm{~kL}$ storage dewar, a cold liquid He pump station for $1200 \mathrm{~g} / \mathrm{s}$ and four transfer lines connecting the four magnets, three toroids and on solenoid.

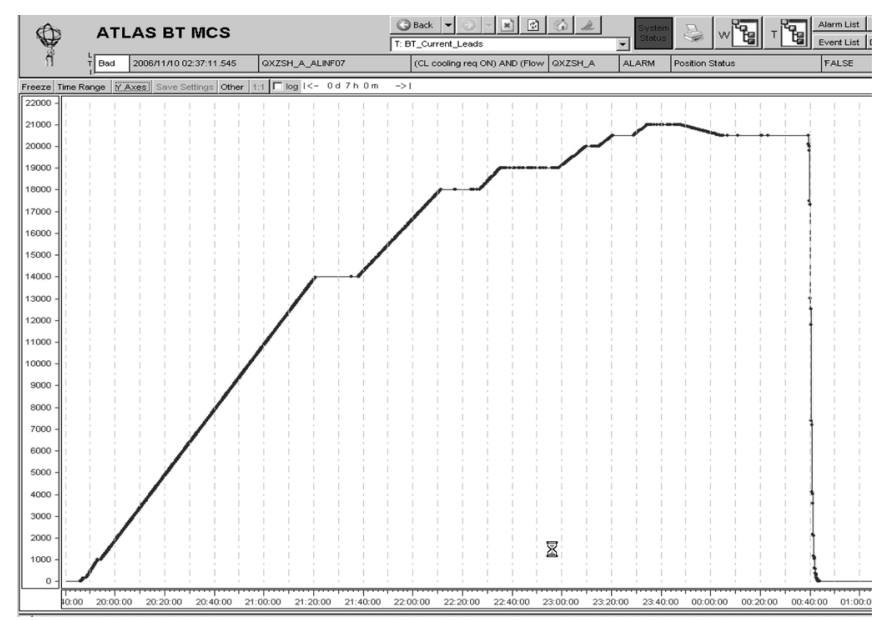

Fig. 4. Barrel toroid test current versus time. Ramp up in steps to $20.5 \mathrm{kA}$, plus 500 A margin to $21.0 \mathrm{kA}$, decrease to $20.5 \mathrm{kA}$ and trigger of fast dump.

reported before [20]. New is the completion of the cryostat integration, the on-surface tests and installation in the cavern of both End Cap Toroids.

Fig. 5 shows the stage of integration of a cold mass in the vacuum vessel before applying superinsulation and vacuum vessel end plate closure. Clearly the eight coil modules interconnected by 8 keystone wedges can be recognized inside the castellated vacuum vessel. The frame visible circumferencing the vessel keeps the vessel in shape during the insertion and the tooling seen in front is for positioning the thermal shields during assembly. The vacuum sealing of the Al alloy vessel is based on double o-rings and it behaved very well. All seals were correctly applied the first time and the He tightness of the vessel is better than $10^{-8} \mathrm{mbar}-\mathrm{l} / \mathrm{s}$. Further details on the End Cap Toroid integration are here [21], [22].

Services connections for helium, current, vacuum pumping and controls are on the top arranged in a turret. Both toroids un-

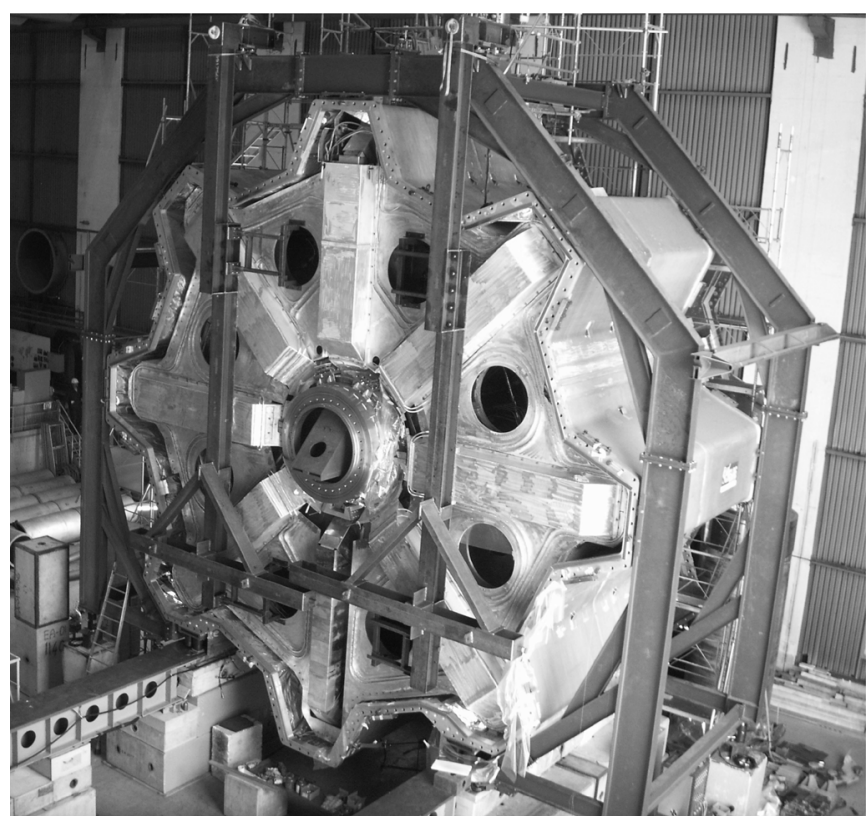

Fig. 5. Cryostat integration of the end cap toroid, shown when cold mass (140 ton) is inserted in the vessel ( 80 ton) and thermal shields are applied to the front face. Next step is to put superinsulation in place and to close the vessel. All services connections are running through a turret connected on top.

derwent a thermal cycling test down to $85 \mathrm{~K}$ before installation. This, to prove that after thermal shrinkage the electrical ground insulation ( $>2 \mathrm{G} \Omega$ at $1 \mathrm{kV}$ ) as well as leak tightness of the cooling lines and thermal shrinkage on the coil suspension rods are sound.

The transport and craning of the 240 ton toroids to their final position in the ATLAS cavern is completed by July 2007. Fig. 6 pictures an End Cap Toroid after transport and just before it enters the surface hall on top of the shaft. Both End Cap Toroids are now being connected to the services systems where after the final cool down will commence.

\section{Full Magnet System Test and Commissioning}

When energizing the three toroids together the End Cap Toroids are pulled towards the center by about 240 ton Lorentz force compressing the Barrel Toroid at either side. A precise alignment is necessary to avoid excessive asymmetric forces on the individual Barrel Toroid cold masses. Therefore the End Cap Toroids are tested first independently, next as a couple and then in combination with the Barrel Toroid, first at low excitation level to adjust if necessary the alignment. Electrically the three toroids are connected in series thus avoiding asymmetry in forces due to different coil currents.

When mechanically adjusted, the entire system will be energized in steps to the nominal current to test normal excitation and fast discharge during provoked quenches. A last step in the commissioning will be a duration test by early 2008 of a week to prove long term stability of the cryogenics system, cold mass temperature and superconductor operation.

\section{CONCLUSION}

The ATLAS Barrel Toroid and Central Solenoid are installed in the cavern, fully tested and behave as expected. 


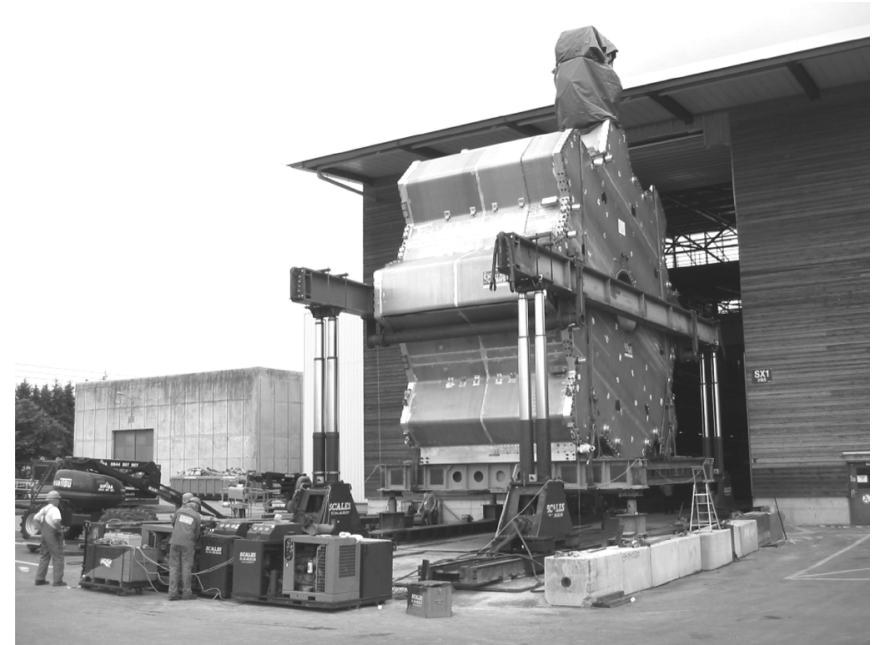

Fig. 6. End cap toroid after transport and in front of the surface building giving access to the shaft and cavern $100 \mathrm{~m}$ underground. Special hydraulic tooling on rails is attached to lift-and-slide the toroid into the building.

After 10 years of construction, the tests demonstrates that superconducting toroids of this size $\left(9500 \mathrm{~m}^{3}\right)$, complexity, peak magnetic field (4 T) and stored energy (1.1 GJ) can be built and operate safely according expectations.

The two End Cap Toroids, of respectable size as well (350 $\mathrm{m}^{3}, 4.1 \mathrm{~T}, 250 \mathrm{MJ}$ each), have been integrated, $80 \mathrm{~K}$ tested and installed as well, but still have to be tested in superconducting state, which is planned for autumn 2007.

When all magnets are fully operational by early 2008 the system is on time for the start of the LHC and ready for hopefully exciting physics experiments.

\section{ACKNOWLEDGMENT}

Greatly acknowledged are those engineers and technicians from the collaborating magnet laboratories who gave their energy and enthusiasm to this project for more than 10 years, CEA-Saclay and INFN-LASA for the Barrel Toroid, RAL and NIKHEF for the End Cap Toroids, KEK for the Central Solenoid, JINR-Dubna for their integration activities and colleagues from CERN service groups for the magnet vacuum-, cryogenic-, electrical-, safety- and control systems.

\section{REFERENCES}

[1] H. H. J. ten Kate, "Superconducting magnet system for the ATLAS detector at CERN," IEEE Tr. Appl. Superconductivity, vol. 9, p. 841, 1999.

[2] H. H. J. ten Kate, "The ATLAS superconducting magnet system: Status of construction \& installation," IEEE Trans. Applied Superconductivity, vol. 16, p. 499, 2006.

[3] A. Yamamoto et al., "Design and development of the ATLAS central solenoid," IEEE Trans. Applied Superconductivity, vol. 9, p. 852, 1999.

[4] R. Ruber, "Ultimate performance of the ATLAS superconducting solenoid," presented at the Appl. Superc. Conf. 2006, Seattle, USA.

[5] A. Yamamoto, Y. Makida, R. Ruber, Y. Doi, T. Haruyama, F. Haug, M. Kawai, Y. Kondo, S. Mizumaki, G. Olesen, E. Sbrissa, K. Tanaka, T. Taylor, and H. H. J. ten Kate, "The ATLAS central solenoid," Nuclear Instruments and Methods, 2007, submitted for publication.
[6] J.-M. Rey, M. Arnaud, C. Berriaud, S. Cazaux, M. Humeau, R. Leboeuf, C. Mayri, P. Vedrine, A. Dudarev, and H. H. J. ten Kate, "Cold mass integration of the ATLAS barrel toroid magnets at CERN," IEEE Trans. Applied Superconductivity, vol. 16, 2006.

[7] P. N. Vedrine, M. Arnaud, C. Berriaud, B. Levesy, C. Mayri, J. M. Rey, A. Dudarev, H. H. J. ten Kate, F. Alessandria, and G. Volpini, "Completion of the manufacturing of the ATLAS barrel toroid magnet at CERN," IEEE Trans. Applied Superconductivity, vol. 16, 2006.

[8] A. Dudarev, J. J. Rabbers, S. Junker, R. Pengo, H. H. J. ten Kate, C. Berriaud, M. Arnaud, P. Vedrine, F. Broggi, and G. Volpini, "On-surface test of the ATLAS barrel toroid coils: Overview," IEEE Trans. Applied Superconductivity, vol. 16, 2006.

[9] C. Beriaud, F. P. Juster, P. Vedrine, A. Dudarev, A. Foussat, F. Broggi, G. Olesen, L. Deront, S. Ravat, R. Pengo, S. Junker, C. Mayri, E. Sbrissa, M. Aranud, J.-M. Rey, G. Volpini, P. Benoit, R. Leboeuf, M. Humeau, V. Stepanov, N. Kopeykin, and H. H. J. ten Kate, "Quench behavior of the ATLAS barrel toroid," presented at the MT-20, Philadelphia, 2007.

[10] C. Beriaud, F. P. Juster, P. Vedrine, A. Dudarev, A. Foussat, F. Broggi, G. Olesen, L. Deront, S. Ravat, R. Pengo, S. Junker, C. Mayri, E. Sbrissa, M. Aranud, J.-M. Rey, G. Volpini, P. Benoit, R. Leboeuf, M. Humeau, V. Stepanov, N. Kopeykin, and H. H. J. ten Kate, "Quench behavior of the ATLAS barrel toroid," IEEE Trans. Applied Superconductivity, 2008, to be published.

[11] R. Pengo, K. Barth, N. Delruelle, M. Pezetti, O. Pirotte, G. Passardi, A Dudarev, and H. H. J. ten Kate, "Cryogenic characteristics of the barrel toroid superconducting magnet," presented at the MT-20, Philadelphia, 2007.

[12] R. Pengo, K. Barth, N. Delruelle, M. Pezetti, O. Pirotte, G. Passardi, A. Dudarev, and H. H. J. ten Kate, "Cryogenic characteristics of the barrel toroid superconducting magnet," IEEE Trans. Applied Superconductivity, 2008, to be published.

[13] N. Delruelle, A. Dudarev, G. Pasardi, R. Pengo, M. Pezetti, O. Pirotte, E. Baynham, C. Mayri, and H. H. J. ten Kate, "First cool-down and test at $4.6 \mathrm{~K}$ of the ATLAS superconducting barrel toroid assembled in the LHC experimental cavern," presented at the MT-20, Philadelphia, 2007.

[14] N. Delruelle, A. Dudarev, G. Pasardi, R. Pengo, M. Pezetti, O. Pirotte, E. Baynham, C. Mayri, and H. H. J. ten Kate, "First cool-down and test at $4.6 \mathrm{~K}$ of the ATLAS superconducting barrel toroid assembled in the LHC experimental cavern," IEEE Trans. Applied Superconductivity, 2008, to be published.

[15] Z. Sun, B. Levesy, M. Massinger, C. Mayri, Y. Pabot, P. Vedrine, I. Zaitsev, A. Dudarev, and H. H. J. ten Kate, "ATLAS barrel toroid warm structure design and manufacturing," IEEE Trans. Applied Superconductivity, vol. 16, 2006.

[16] A. Foussat, M. Raymond, H. H. J. ten Kate, B. Levesy, C. Mayri, P. Vedrine, Z. Sun, and Y. Pabot, "Assembly concept and technology of the ATLAS barrel toroid," IEEE Trans. Applied. Supercond., vol. 16, 2006.

[17] C. Mayri, P. Vedrine, C. Berriaud, M. Reytier, Y. Pabot, S. Cazaux, A. Foussat, A. Dudarev, Y. Zaitsev, and H. H. J. ten Kate, "Suspension system of the barrel toroid cold mass," IEEE Trans. Applied Superconductivity, vol. 16, 2006.

[18] A. Foussat, H. H. J. ten Kate, A. Dudarev, H. Bajas, P. Védrine, C. Berriaud, Z. Sun, and M. Sorbi, "Mechanical commissioning of the ATLAS barrel toroid magnet," presented at the MT-20, Philadelphia, 2007, unpublished.

[19] A. Foussat, H. H. J. ten Kate, A. Dudarev, H. Bajas, P. Védrine, C. Berriaud, Z. Sun, and M. Sorbi, "Mechanical commissioning of the ATLAS barrel toroid magnet," IEEE Trans. Applied Superconductivity, 2008, to be published.

[20] D. E. Baynham, F. S. Carr, E. Holtom, J. Buskop, A. Dudarev, P. Benoit, R. Ruber, R. Pengo, G. Vandoni, and H. H. J. ten Kate, "ATLAS end cap toroid integration and test," IEEE Trans. Applied Superconductivity, 2008, vol. 17, 2007.

[21] D. E. Baynham, F. S. Carr, E. Holtom, J. Buskop, A. Dudarev, G. Vandoni, R. Ruber, A. Foussat, M. Losasso, P. Benoit, R. Pengo, L. Stewart, A. Olyunin, V. Stepanov, N. Kopeykin, I. Shugaev, M. Arnaud, and H. H. J. ten Kate, "ATLAS end cap toroid final integration, test and installation," presented at the MT-20, Philadelphia, 2007, unpublished.

[22] D. E. Baynham, F. S. Carr, E. Holtom, J. Buskop, A. Dudarev, G. Vandoni, R. Ruber, A. Foussat, M. Losasso, P. Benoit, R. Pengo, L. Stewart, A. Olyunin, V. Stepanov, N. Kopeykin, I. Shugaev, M. Arnaud, and H. H. J. ten Kate, "ATLAS end cap toroid final integration, test and installation," IEEE Trans. Applied Superconductivity, 2008, to be published. 